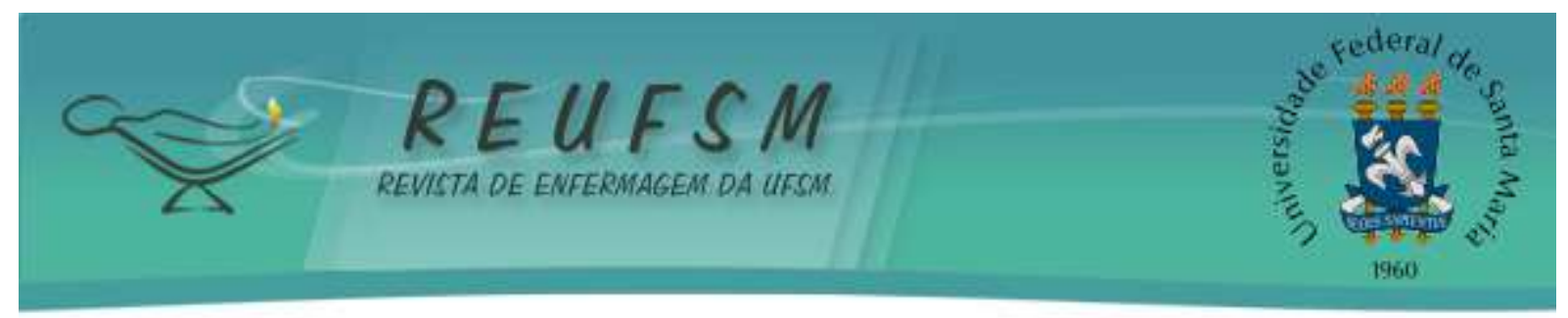

\title{
ESTRATÉGIAS DE ENFRENTAMENTO UTILIZADAS PELA EQUIPE DE ENFERMAGEM NO CUIDADO AO PACIENTE ONCOLÓGICO E FAMÍLIA
}

\section{COPING STRATEGIES USED BY THE NURSING STAFF IN CARING FOR CANCER PATIENTS AND FAMILY}

\author{
ESTRATEGIAS DE ENFRENTAMIENTO UTILIZADAS POR EL EQUIPO DE \\ ENFERMERÍA EN EL CUIDADO DE LOS PACIENTES CON CÁNCER Y FAMILIA
}

\author{
Pamela Karin Lazzaroto ${ }^{1}$ \\ Kátia Lilian Sedrez Celich ${ }^{2}$ \\ Silvia Silva de Souza ${ }^{3}$ \\ Marcela Martins Furlan de Léo ${ }^{4}$ \\ Tatiana Gaffuri da Silva ${ }^{5}$ \\ Leoni Terezinha Zenevicz ${ }^{6}$
}

Doi: $10.5902 / 2179769229408$

RESUMO: Objetivo: identificar as estratégias de enfrentamento/coping utilizadas pela equipe de enfermagem no cuidado ao paciente oncológico e família, em âmbito hospitalar. Método: estudo exploratório descritivo, com abordagem qualitativa, baseado no referencial de Lazarus e Folkman sobre coping. A pesquisa foi desenvolvida com oito integrantes da equipe de enfermagem de uma unidade oncológica hospitalar no oeste catarinense, que responderam a uma entrevista semiestruturada a respeito de seus enfrentamentos/coping no cotidiano de trabalho em oncologia. A análise das informações ocorreu por meio da análise temática. Resultados: apontaram o coping focalizado na emoção: fuga-evitamento e reavaliação positiva e o coping focalizado no problema: resolução planejada, suporte social e autocontrole. Considerações finais: o cotidiano de cuidado em oncologia desperta sofrimento, situação que conduz o desenvolvimento de várias formas de manejo para enfrentar esta realidade e promover adaptação e bem-estar.

Descritores: Adaptação psicológica; Enfermagem oncológica; Apego ao objeto; Relações interpessoais

ABSTRACT: Aim: to identify the coping strategies used by nursing staff in caring for cancer patients and family in the hospital environment. Method: a descriptive exploratory study with a qualitative approach based on the reference of Lazarus and Folkman on coping. The research was developed with eight members of the nursing staff of a hospital oncology unit in the East of Santa Catarina, who responded to a semi-structured interview about their coping

\footnotetext{
${ }^{1}$ Enfermeira. Pós-graduada em enfermagem oncológica. Centro Sul-Brasileiro de Pesquisa, Extensão e PósGraduaçao. Chapecó, SC, Brasil. E-mail: pame_lazzaroto@ hotmail.com

${ }^{2}$ Enfermeira. Doutora em geriatria e gerontologia biomédica. Pontifícia Universidade Católica do Rio Grande do Sul - PUCRS. Grupo de Pesquisa: Gepegece da UFFS. Chapecó, SC, Brasil. E-mail: katia.celich@uffs.edu.br ${ }^{3}$ Enfermeira. Mestre em enfermagem. Universidade Federal de Santa Catarina. Grupo de Pesquisa: Gepegece da UFFS. Chapecó, SC, Brasil. E-mail: silvia.souza@uffs.edu.br

${ }^{4}$ Enfermeira. Doutora em ciências. Escola de Enfermagem de Ribeirão Preto - USP. Grupo de Pesquisa: Gepegece da UFFS. Chapecó, SC, Brasil. E-mail: marcela.leo@uffs.edu.br

${ }^{5}$ Enfermeira. Mestre em Ciências da Saúde Humana. Universidade Federal de Santa Catarina. Grupo de Pesquisa: Gepegece da UFFS. Chapecó, SC, Brasil. E-mail: tatiana.silva@uffs.edu.br

${ }^{6}$ Enfermeira. Doutora em Gerontologia Biomédica. Pontifícia Universidade Católica do Rio Grande do Sul PUCRS. Grupo de Pesquisa: Gepegece da UFFS. Chapecó, SC, Brasil. E-mail: leoni.zenevicz@uffs.edu.br
} 


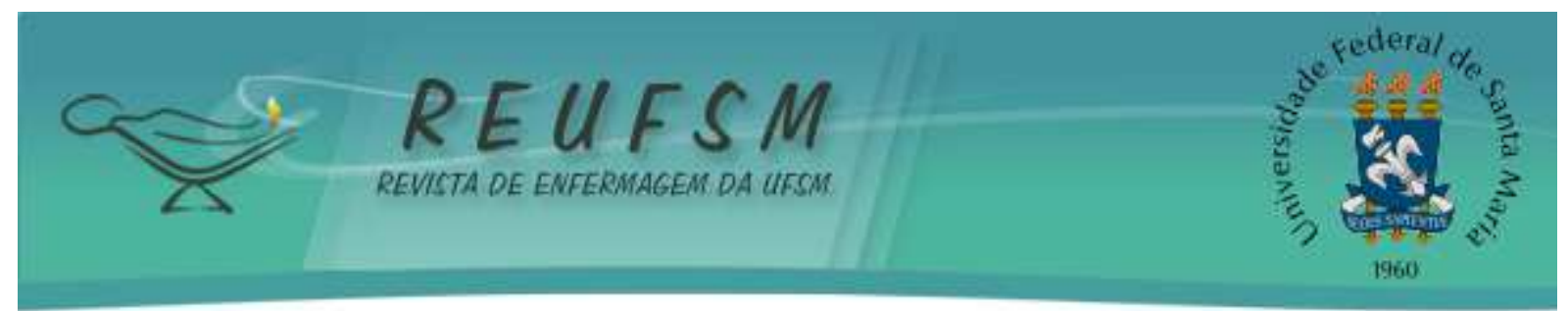

in the daily work in oncology. The information analysis occurred by means of thematic analysis. Results: The ones that pointed the emotion-focused coping were the following: escape-avoidance and positive reevaluation and coping focused on the problem: planned resolution, social support and self-control. Final Notes: the daily care in oncology awakens suffering, a situation that leads to the development of various forms of handling in order to face this reality and promote adaptation and well-being.

Descriptors: Psychological adaptation; Oncologic nursing; Attachment to the object; Interpersonal relationships

RESUMEN: Objetivo: identificar las estrategias de enfrentamiento utilizadas por el equipo de enfermería en el cuidado de los pacientes con cáncer y familiares en el contexto hospitalario. Método: estudio exploratorio, descriptivo, con un enfoque cualitativo, basado en la referencia de Lazarus y Folkman sobre el enfrentamiento/coping. La investigación fue desarrollada con ocho miembros del equipo de enfermería, en la unidad de oncología de un hospital en el Oeste de Santa Catarina, la recolección de datos ocurrió por medio de una entrevista semi-estructurada sobre los enfrentamientos en el trabajo diario en oncología. El análisis de esos datos fue realizado por medio de análisis temático. Resultados: se evidenció el coping centrado en las emociones: escape-evitación y reevaluación positiva; y el enfrentamiento con énfasis en el problema: la resolución planificada, el apoyo social y el auto-control. Consideraciones finales: el cotidiano del cuidado diario en oncología puede provocar sufrimiento, esa situación produce el desarrollo de diferentes formas de gestión con el objetivo de comprender esa realidad y promover la adaptación y el bienestar.

Descriptores: Adaptación psicológica; Enfermería oncológica; Apego al objeto; Relaciones interpersonales

\section{INTRODUÇÃO}

O câncer é uma doença de relevância mundial devido a sua alta incidência e morbimortalidade, atingindo 582 mil casos, sendo 300 entre homens e 282 entre mulheres, com previsão de 1,2 milhão casos novos no Brasil entre 2018 e 2019, reforçando a magnitude do problema. ${ }^{1}$ É uma doença crônica que está associada a sofrimento, dor, angústia, afastamento do convívio familiar e social e medo da morte, exigindo a qualificação permanente de profissionais de saúde para atender peculiares desta população em constante crescimento. ${ }^{2-3} \mathrm{~A}$ isso, soma-se a alta complexidade que o cuidado com este paciente demanda, devido às especificidades do tratamento e às diversas complicações que pode apresentar.

Uma revisão de literatura indica que as reações emocionais e comportamentais despertadas em enfermeiros brasileiros em oncologia são semelhantes aos experenciados por pacientes e seus familiares, incluindo sentimentos de impotência, negação, raiva, culpa, pensamento mágico e sintomas depressivos. Normalmente, estes estão associados ao isolamento social, expondo a dimensão psicológica e social da problemática. ${ }^{4}$ 


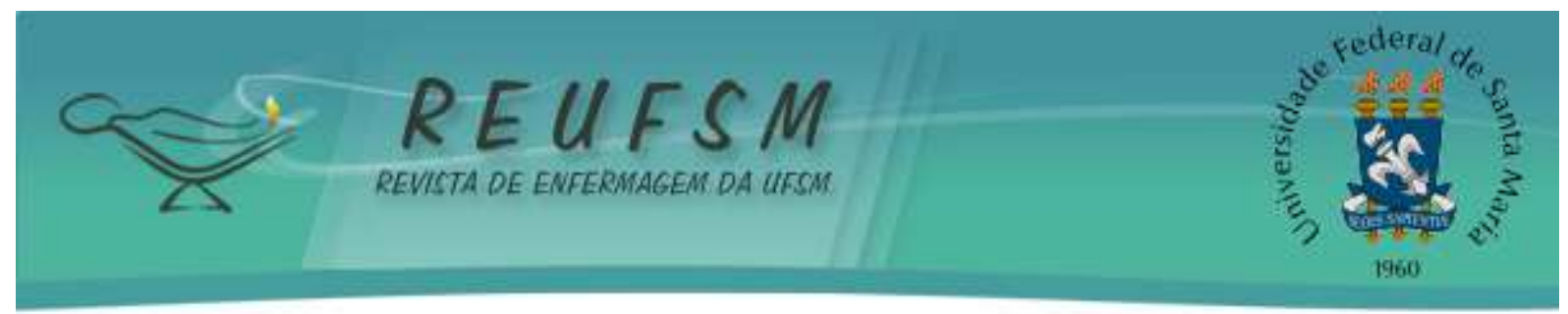

É neste contexto de intensa sobrecarga que os profissionais de enfermagem convivem diariamente com sentimentos que podem implicar desgaste físico e emocional, tornando-os vulneráveis frente ao convívio com o paciente oncológico e ao contato com todo o estigma associado a esta doença. ${ }^{5}$ Ao acolher o paciente e sua família de maneira integral, adentram no mundo por eles vivido, participando dos desafios no processo da doença e do tratamento. Desta forma, em muitas situações, entram em contato com a finitude humana, que o remete a sua própria consciência sobre ser finito, sendo natural e necessário aos profissionais desenvolverem estratégias de enfrentamento que promovam o autocontrole e minimizem a angústia nas relações de convívio.

O enfrentamento/coping se constitui como um conjunto de esforços cognitivos e comportamentais, atitudes e estratégias aprendidas e desenvolvidas pelo indivíduo para o manejo de situações estressoras, internas ou externas, mobilizados pelo indivíduo com o objetivo de controlar ou dominar a situação de ameaça e, assim, se adaptar ao meio e/ou à realidade. Sua característica determinante é a intencionalidade, ou seja, o sujeito identifica um estímulo como estressor e se mobiliza conscientemente para administrá-lo, protegendo sua sanidade física e mental, o que exclui reações inconscientes de defesa psíquica, como a negação, regressão ou somatização. ${ }^{6}$

Segundo o referencial teórico de Lazarus e Folkman, as estratégias de enfrentamento/coping centradas na emoção são caracterizadas pela tentativa de regular o estado emocional diante do estresse, sendo, usualmente, derivadas das reações de defesa psíquica, que tentam proteger a pessoa do confronto com a realidade ameaçadora. Estas estratégias de coping são dirigidas tanto ao nível somático e/ou de sentimentos, com o intuito de trazer equilíbrio emocional ao indivíduo, reduzindo a sensação física desagradável do estado de estresse. O coping focalizado no problema é definido como esforços/estratégias utilizadas para intervir na situação que origina o estresse, na intenção de modificá-la e de melhorar a relação da pessoa com o ambiente gerador de tensão. ${ }^{6}$

À medida que se lança mão das estratégias de coping, o indivíduo reavalia sua condição física e emocional em relação ao estado inicial de exposição ao estímulo estressor. Assim, remanejando estratégias, descartando as que considerou menos eficazes ou interrompendo o processo, no caso de sentir-se aliviado, o que sinaliza o caráter dinâmico do manejo de estratégias de coping. A adoção ou descarte de estratégias dependerá da 


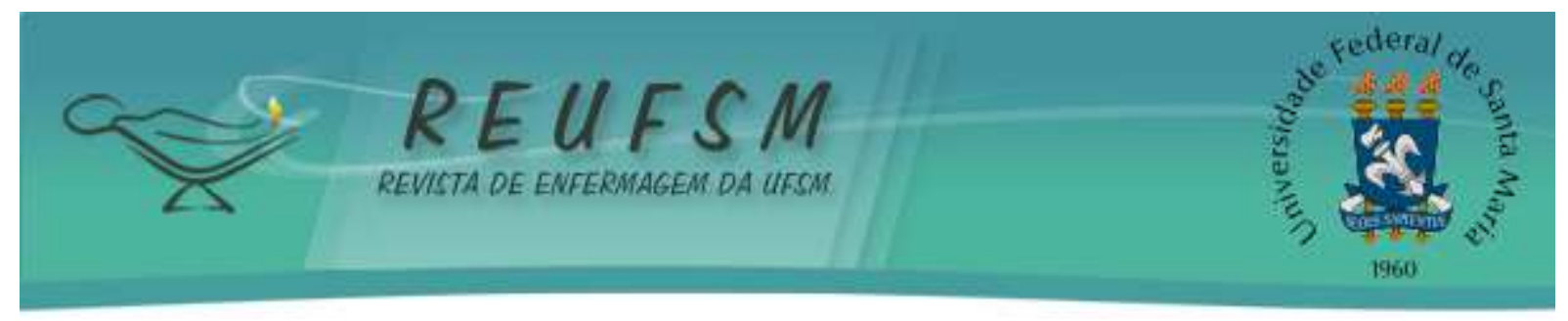

interpretação singular e das experiências anteriores de regulação, do nível de estresse do sujeito a respeito dos estímulos, que geraram esse movimento de enfrentamento. ${ }^{7}$

Uma revisão integrativa recente, que investigou estratégias de enfrentamento em enfermeiros que desenvolvem cuidados paliativos junto a pacientes oncológicos, ressalta a relevância da construção de conhecimento sobre esta temática para subsidiar o monitoramento e gestão dos processos de trabalho inerentes a estes profissionais. O estudo também recomenda novas pesquisas que elucidem as estratégias de coping manejadas por enfermeiros na assistência a pessoas com câncer. A revisão não identificou estudos brasileiros a respeito do tema, especificamente em cuidados paliativos em oncologia. ${ }^{8}$

Apesar da atual produção brasileira sobre sofrimento e agravos psiquiátricos em enfermeiros ou na equipe de enfermagem no cotidiano do cuidado oncológico, ${ }^{9-10}$ que caracteriza o trabalho com esta clientela uma realidade estressora para o profissional e que recomenda o aprofundamento das investigações a respeito, evidencia-se a escassez de trabalhos sobre como esses profissionais enfrentam a problemática, em relação às estratégias de coping. Tal achado gerou a questão da presente investigação: como profissionais de enfermagem se mobilizam intencional e internamente para suportar o cotidiano de trabalho em oncologia, de forma a preservar sua saúde mental e garantir o cuidado de enfermagem de qualidade?

Diante da repercussão estatística internacional do câncer, das demandas e da complexidade de atenção a esta população e da constatação de sofrimento e impacto psicossocial do cuidado oncológico em indivíduos que atuam na saúde, o presente estudo se justifica ao investigar as estratégias de coping construídas e manejadas por profissionais de enfermagem no contato usual com o paciente oncológico e seus familiares.

A produção deste conhecimento é relevante à medida que subsidia o autocuidado dessa categoria e instiga intervenções institucionais de gestão que favoreçam a equipe de enfermagem em oncologia. E que primem pela saúde mental desses cuidadores, essencial para a qualidade e a eficácia do trabalho que garanta um impacto decisivo nos cuidados prestados. ${ }^{11}$

Assim, objetivou-se identificar as estratégias de enfrentamento/coping utilizadas pela equipe de enfermagem no cuidado ao paciente oncológico e família, em âmbito hospitalar. 


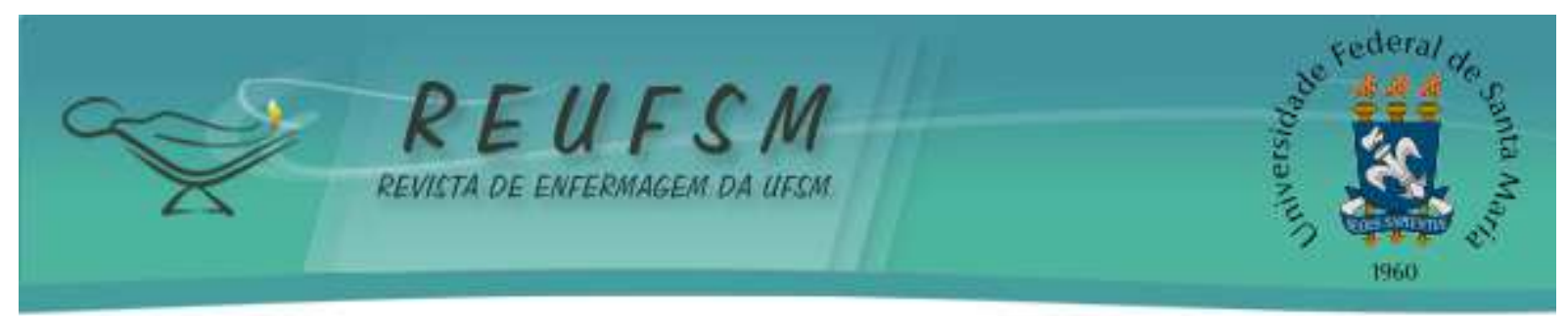

\section{MÉTODO}

Estudo descritivo, exploratório, com abordagem qualitativa, fundamentado no referencial teórico metodológico de Lazarus e Folkman sobre estratégias de enfrentamento ou coping. ${ }^{6}$ Realizado no Setor de Internação Oncológica de um Hospital Geral de médio porte, com duzentos e noventa e sete leitos, considerado referência em Oncologia clínica e cirúrgica, na Região Oeste de Santa Catarina. O setor oncológico atende pacientes clínicos e cirúrgicos e dispõem de cinco enfermeiros e dezesseis técnicos em enfermagem em seu quadro funcional de enfermagem.

A aproximação com o campo do estudo correu na nona fase do curso de graduação em Enfermagem, durante desenvolvimento de 400 horas da disciplina de Estágio Supervisionado no setor de oncologia, no primeiro semestre de 2016. Momento que instigou a questão da pesquisa.

Participaram do estudo, membros da equipe de enfermagem que prestavam cuidado direto ao paciente oncológico adulto e sua família nos três turnos de trabalho (manhã, tarde e noite). Como critério de inclusão considerou-se: atuar há mais de seis meses na assistência ao paciente oncológico, sendo excluídos os que estavam em licença de saúde ou maternidade durante o período de coleta das informações. Dos cinco enfermeiros do setor, dois integraram a pesquisa, dentre os demais, um estava em férias e dois atuavam no setor há menos de seis meses. Com relação aos técnicos, seis trabalham por tempo superior ao mínimo requerido na pesquisa.

A entrada no campo para coleta de dados respeitou integralmente os preceitos éticos que envolvem pesquisas com seres humanos, dispostos pela resolução n.466/12 do Conselho Nacional de Saúde, incluindo aprovação no dia 26/06/2016 pelo Comitê de Ética em Pesquisa da Universidade Federal da Fronteira Sul - UFFS, sob o parecer número 1.607.319, bem como a anuência dos participantes da pesquisa mediante assinatura do Termo de Consentimento Livre e Esclarecido.

A coleta das informações utilizou entrevista semiestruturada individual, desenvolvida no mês de agosto e setembro de 2016 com duração média de cinquenta minutos, seguindo um roteiro pré-estabelecido, com duas questões: Relate alguma situação que gerou sofrimento ao cuidar do paciente oncológico e família. Como você reagiu a ela? As entrevistas foram áudiogravadas e ocorreram em um local pré-determinado, agendado em comum acordo entre participante e pesquisador. Sete participantes optaram por realizar a entrevista no local de trabalho e um optou pela residência. O término da entrevista deu-se no momento em que o pesquisador entendeu como suficientes as informações coletadas (saturação). ${ }^{12}$ 


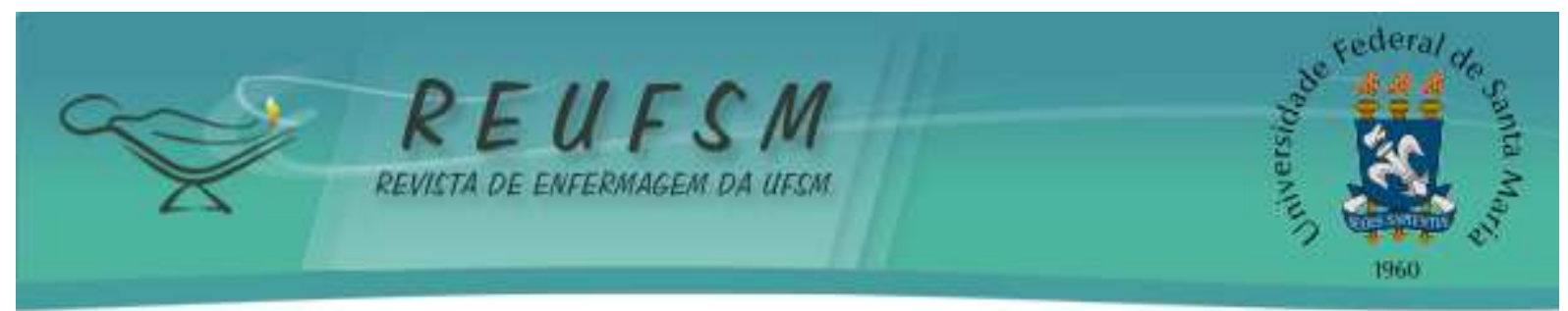

A saída do campo deu-se com o término das entrevistas, sendo efetivado o compromisso de retorno para validação das falas e compartilhamento dos resultados. Após cada entrevista, as gravações foram transcritas na íntegra, com anotações complementares acerca da impressão sobre o entrevistado, bem como aspectos gestuais e expressões faciais, que posteriormente ajudaram na interpretação das falas dos participantes do estudo. Com a finalidade de manter o anonimato e organizar os registros, os participantes foram identificados pela letra "E", significando Entrevistado, seguido pelo número arábico (1, 2, 3...), conforme a cronologia em que ocorreram as entrevistas, ex. E1.

A análise dos dados ocorreu por meio da análise de conteúdo temático, constituída por três fases. Na primeira fase, foi realizada leitura flutuante das entrevistas transcritas na íntegra. $\mathrm{Na}$ segunda etapa, a leitura das entrevistas com maior profundidade possibilitou a codificação das falas nas unidades de significação pré-determinadas, conforme referencial da teoria do enfrentamento de Lazarus e Folkman, assim determinadas: Estratégias de enfrentamento focadas na emoção e estratégia de enfrentamento focada no problema. Na terceira e última etapa, foi estabelecida relação entre os resultados do estudo e a literatura pertinente ao tema. ${ }^{12}$

Convém destacar que, ao término da primeira e segunda etapa, anterior à discussão dos dados, as entrevistas foram validadas pelos participantes, com entrega do material físico e por e-mail para leitura e prazo para devolutiva de cinco dias pelo sistema eletrônico ou em visita realizada pela pesquisadora. Todos emitiram concordância dos dados por $e$-mail.

\section{RESULTADOS}

As estratégias de enfrentamento identificadas e analisadas no estudo são focadas na emoção (fuga-evitamento e reavaliação positiva) e focadas no problema (resolução planejada, suporte social e autocontrole).

\section{Estratégias focadas na emoção}

A estratégia mais evidenciada pela equipe de enfermagem foi a fuga-evitamento ou fuga-esquiva.

Eu saio pouco, fico mais com a minha filha, converso outras coisas em casa, sobre a faculdade e o trabalho dela [...] quando estou em casa não penso muito, foco mais no meu trabalho em casa, trabalho doméstico, essas coisas, não fico pensando muito no trabalho do hospital. (E3) 


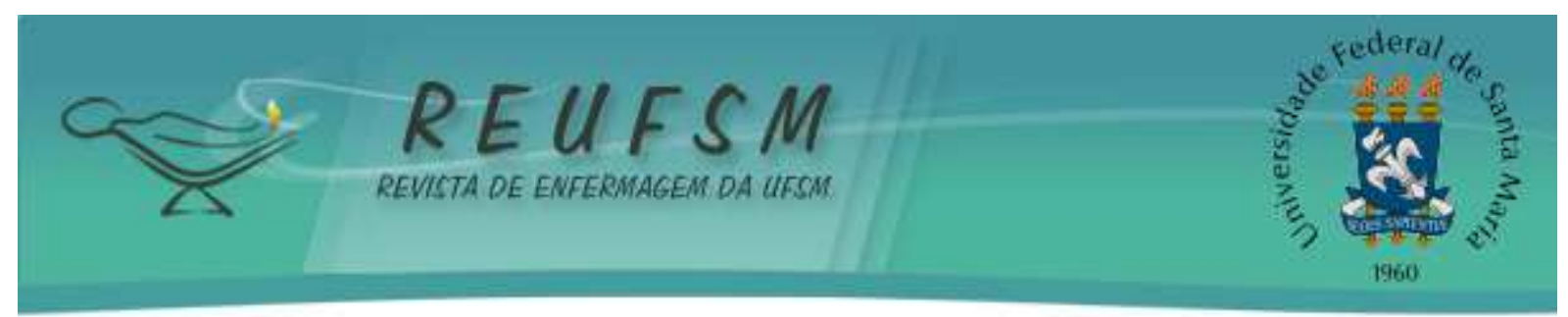

[...] eu gosto de ler, assistir filme, jogar, brincar com o meu neto [...] eu sempre tenho coisas para fazer em casa. (E5)

Ao agirem desta maneira utilizam, como estratégia de fuga-evitamento, o distanciamento daquele que representa a terminalidade da vida.

Não gosto de criar vínculos [...] são pessoas que geralmente vão morrer, aí eu não gosto de ficar com essas lembranças. (E5)

Na maioria das vezes eu tento fingir que eu não estou vendo aquilo [ele morrendo], eu tento lidar com a parte humana, sem me envolver emocionalmente. (E6)

Fazes o que tem para fazer, tenta não ter contato muito com o paciente [...] é muito triste ver ele daquele jeito [...] porque sabes que depois vais sofrer também. (E7)

Faço o que tenho que fazer, é automático, é no robô, tu vai lá, leva a bacia, pega, tira, não foca na pessoa, faz o teu serviço, porque se não tu não consegue fazer, ai tu pensa assim, vamos lá eu estou trabalhando, tenho que fazer, meio que sei lá que parte do teu cérebro tu bloqueia, eu não estou vendo a pessoa, tenho que fazer isso e pronto! (E4)

A estratégia fuga da realidade aparece como tentativa de ludibriar a ansiedade, a angústia, o sofrimento e a tristeza causada nas relações com o paciente e seus familiares.

Ai eu fui para o banheiro chorar, para que ela não me visse chorando também. (E5)

Ninguém olha para nós, neste um ano que trabalho aqui é a primeira vez que falo, ninguém vê a gente, eu escolhi estar aqui, mas eu não sabia que seria assim, se fosse antes eu faria a mesma escolha, mas é muito sofrido [...] as pessoas aqui são amarguradas ou fingem que não se importam. (E6)

Não chorava aqui, aqui eu tentava ficar forte, mas em casa eu chorei, no começo foi muito difícil, segurar para não chorar na frente da família. (E7)

Outra estratégia de enfrentamento focada na emoção identificada no estudo é a ressignificação do evento, que é a tentativa do indivíduo de criar soluções alternativas para o problema ou visualizá-lo de um modo positivo. ${ }^{6}$ Esta forma de dimensionar a situação estressora por um prisma mais positivo pode ser evidenciada:

[...] aproveitar mais os momentos que tenho com a família, não sabemos até quando, nesse sentido, me mudou bastante, é dar valor para as coisas que tenho, não materiais, mas a tua família, me fez crescer bastante. (E4) 


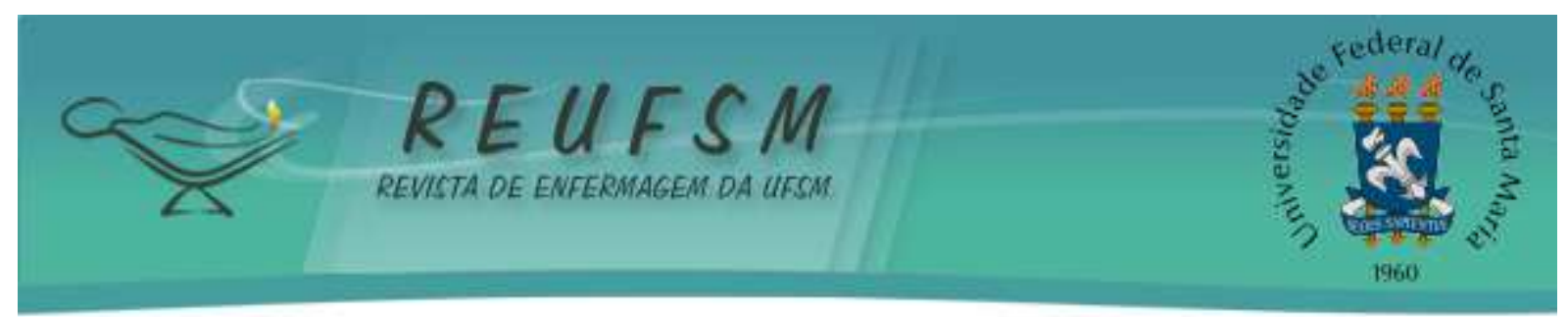

[...] depois que eu comecei a trabalhar aqui, que eu ouvi umas histórias, comecei a pensar: será que vale a pena se incomodar tanto? Se estressar tanto com coisas insignificantes? Às vezes a gente tem tudo e não agradece. Depois que eu comecei a trabalhar aqui, comecei a agradecer mais do que pedir. (E7)

As falas revelam que os profissionais de enfermagem realizam uma reavaliação positiva da situação, numa tentativa de manter o controle sobre o causador de estresse. É interessante observar que, além do aspecto de ressignificação da própria vida, os profissionais demonstram claramente de que maneira a solidariedade pode ser utilizada como estratégia frente ao estresse.

Procuro fazer de tudo para dar conforto, liberar visitas, acompanhante e alimentação. A gente acaba fazendo todas as vontades que ele tem. (E1)

Eu trato ele como se fosse da minha família, como se fosse pela minha tia eu sei que eu faria o melhor e eles também merecem o melhor. (E6)

\section{Estratégias focadas no problema}

Foram identificadas três estratégias de enfrentamento focadas no problema: "resolução planejada", o "suporte social" e autocontrole". O relato a seguir implica a resolução planejada, expressa a seguir:

Me deixa triste não poder deixar o paciente num quarto sozinho quando ele precisa, me sinto impotente [...] tento negociar com a internação, flexibilizar as rotinas. (E8)

Os participantes do estudo desenvolvem outra estratégia focada no problema, a busca por suporte social, que descreve os esforços de procura por auxílio informativo, apoio tangível e emocional, revelando a carência deste amparo institucional:

Eu acho que o apoio psicológico é importante, mas o pessoal que trabalha na oncologia deveria folgar com mais frequência, ter um sistema de folgas diferenciadas, por que às vezes tu precisas sair para encontrar amigos, por que tem semanas que falecem 5 pacientes que estão contigo a 80 dias [...] tu precisas perder o contato com a oncologia para se distrair. (E1)

A realização de grupos com a psicologia e os funcionários ia motivar mais, não precisava ser um acompanhamento direto, mas que fosse para motivação dos funcionários. (E4)

Uma das estratégias utilizada também foi o autocontrole, que é a utilização de esforços de regulação dos próprios sentimentos e ações. ${ }^{6}$ 


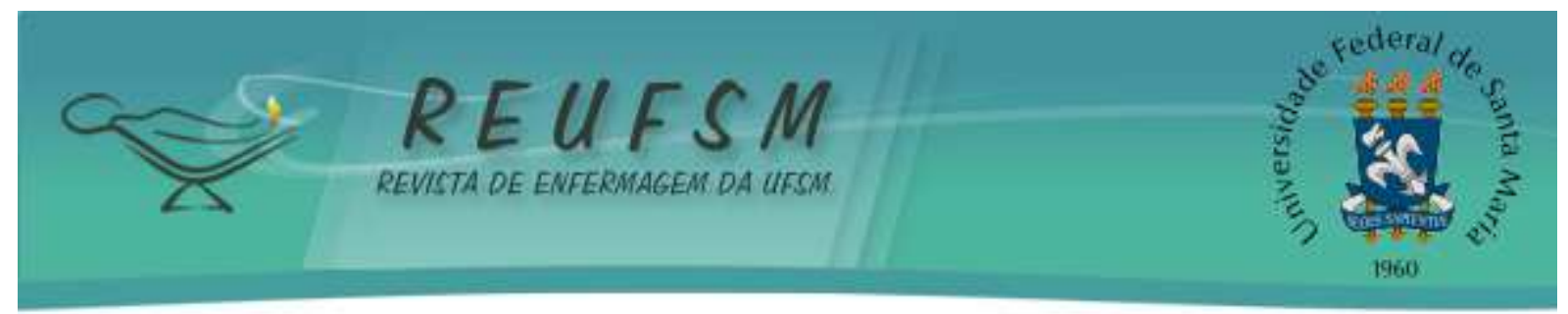

Não choro à toa, eu ajo bem normal, mas não vou chorar, bloqueio meus sentimentos, vou e faço o meu trabalho, bem tranquila. (E2)

Parei e pensei, eu tenho que parar um pouco, às vezes eu tenho medo de ser grosseira com os pacientes, você está com um monte de problemas ali nesse dia a dia, nessa correria. (E3)

Na frente do paciente eu me controlo e não choro, mas quando chego em casa embaixo do chuveiro não consigo segurar o choro. (E7)

As falas demonstram que os profissionais tentam controlar suas emoções guardando os sentimentos para si mesmos.

O estudo desvelou a busca pela religiosidade e espiritualidade como uma estratégia significativa para suportar o cotidiano de cuidado:

Peço tanto para que Deus proteja eles e que dê força, por que é muito difícil. (E3)

O tratamento é uma surpresa, então primeiro tem que se decidir qual é o significado da vida, que valor a questão espiritual tem para o indivíduo, isso ajuda bastante, primeiro definir o teu conceito próprio, para depois conseguir intermediar com o paciente. (E8)

\section{DISCUSSÃO}

Foi possível identificar que os profissionais buscam, nas ações do seu dia a dia, encontrar meios de reduzir os danos ocupacionais relacionados ao cuidado do paciente oncológico e sua família. ${ }^{13}$ Os profissionais de oncologia, normalmente, evitam encarar a eminência da morte, devido ao sofrimento que a vivência desta situação pode causar. ${ }^{14}$ Das falas, depreende-se que a estratégia de enfrentamento adotada pela equipe reflete a dificuldade que o ser humano tem de conviver com a finitude, pois se depara com um de seus maiores temores, a morte. Ao presenciar o outro morrendo, é possível se perceber como um ser mortal, no entanto, ele jamais compreenderá sua real dimensão.

O distanciamento de uma situação estressora pode ser resultado de mecanismos de defesa utilizados para proteger o sujeito do evento estressor. Porém, isso precisa ser diferenciado de estratégias de coping, que são conscientemente adotadas e abandonadas para resolver a situação ou promover adaptação, minimizando sofrimento e maximizando satisfação. A repressão ou negação dos sentimentos pode causar fadiga, cansaço e estresse, algo frequente em alguns profissionais, ${ }^{15}$ e é para evitar esses resultados catastróficos sobre a qualidade de vida que o profissional precisa mobilizar continuamente estratégias de coping. Esta é uma questão chave 


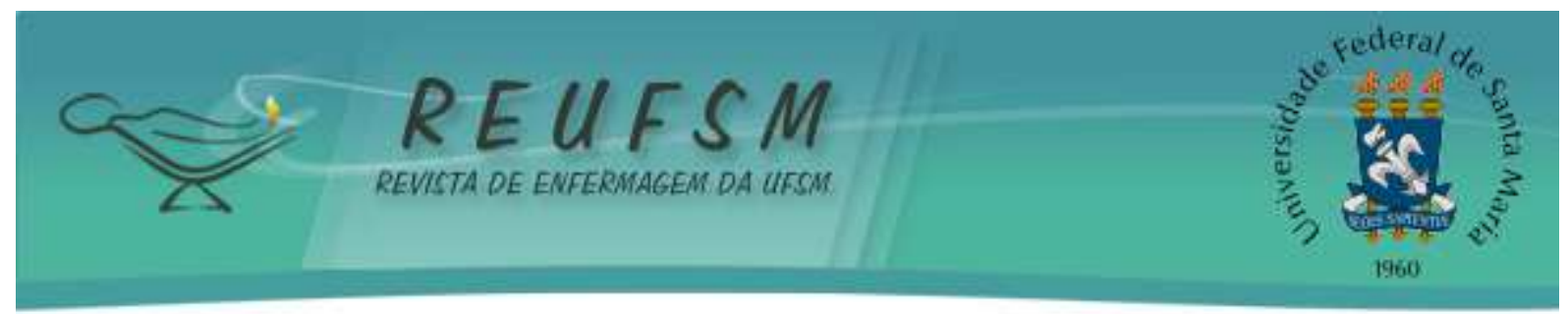

para a compreensão do núcleo do presente estudo, como os profissionais de enfermagem se movimentam nesse ambiente de dor para não adoecerem, ao entrar em contato com a sua própria dor no contato com o outro que representa as suas próprias fragilidades, enquanto humano.

Em oncologia, o profissional está exposto a uma atmosfera de sentimentos, principalmente negativos, os quais podem causar danos que se refletem na dimensão emocional, social e nos aspectos da assistência, podendo levar ao afastamento do paciente ou, até mesmo, ao abandono de seus deveres. ${ }^{5,16}$ Esta atitude pode refletir de forma negativa na qualidade do atendimento ao paciente, bem como transformar este cuidado em algo mecanizado, como identificou-se nos discursos que expressam reações de fuga-evitamento: ao se distanciar afetivamente do paciente, $a$ priori o profissional se protege, evitando o sentimento de dor; entretanto, esta armadura, intencionalmente vestida, que parte de experiências pessoais anteriores, esteriliza os relacionamentos e vai além, prejudicando as suas relações sociais e familiares.

Estudo realizado com enfermeiras do setor de hemato-oncologia constatou a utilização da estratégia de coping fuga-esquiva em $37,5 \%$ destes indivíduos sinalizando que elas sentem dificuldades em lidar com determinadas situações que ocorrem com o paciente oncológico. Também se constatou que o comportamento de fuga-esquiva é um modo de fantasiar sobre possíveis soluções para os problemas sem tomar atitudes de fato modificáveis. As pesquisadoras consideram a esquiva como uma estratégia consciente em relação à ameaça, caracterizando uma tentativa de normalizar o impacto emocional do estresse, com isso, faz com que estas se tornem menos adaptativas do que as centradas no problema. ${ }^{17}$

Nas falas apresentadas, os membros da equipe de enfermagem demonstram sofrer intensamente, muitas vezes ocultando seus sentimentos e reagindo artificialmente ao contato com paciente e familiares. O receio de demonstrar seus sentimentos é algo aprendido no decorrer da formação profissional, sendo estimulado a mascarar suas emoções, que podem demonstrar fragilidade. As estratégias de afastamento podem levar o indivíduo a um agravamento do estado de sofrimento, com consequente busca por alívio a partir do álcool, drogas, fumo e fármacos, repercutindo no absenteísmo. ${ }^{18}$

Ainda que expressem sofrimento, das falas depreende-se que os profissionais buscam ressiginifcar seu papel e avalia-lo de forma positiva, ajudando o paciente e a família, que neste momento encontram-se fragilizados, necessitando de amparo. Solidarizar-se com o outro inclui 


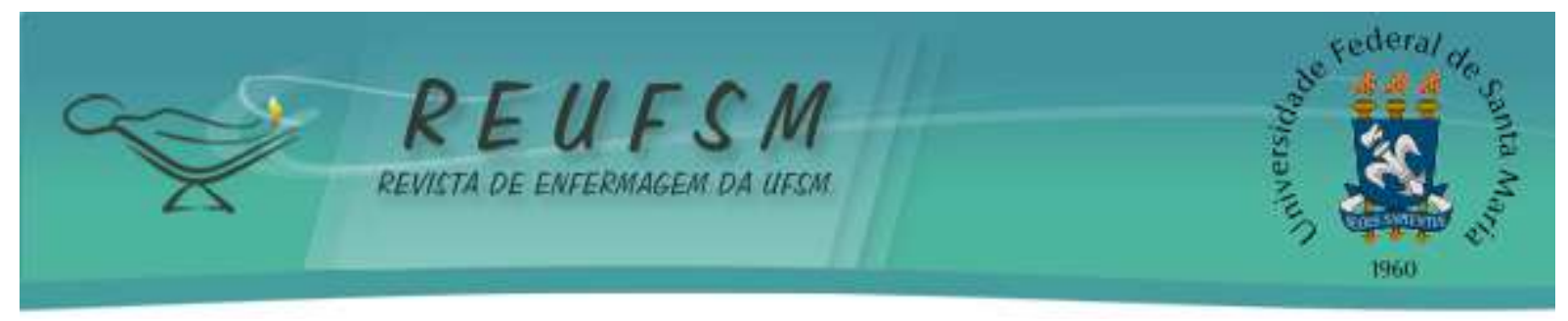

perceber a vulnerabilidade, suas necessidades de cuidado e disponibilidade em um agir compreensivo, remetendo a ideia de responsabilidade recíproca pelo bem-estar do ser cuidado. ${ }^{19}$

Não existem estratégias de enfrentamento certas ou erradas; à medida que se desenvolve um ferramental de estratégias de coping ao longo de nossa existência, podem-se eleger as mais apropridas ou eficazes, bem como lançar mão de novos recursos apreendidos, para um alcançar um resultado satisfatório de adaptação ou de modificação da situação. Recomenda-se que a equipe de enfermagem mantenha o equilíbrio e o autocontrole frente às determinadas situações vivenciadas com o paciente oncológico e sua família, ${ }^{6}$ sendo imprescindível o desenvolvimento consciente de estratégias, sobretudo as centradas no problema, que possam minimizar os efeitos desta convivência, podendo tornar o cotidiano da equipe mais produtivo e menos desgastante. ${ }^{20}$

Estudo sobre estratégias de enfrentamento utilizadas pela equipe de enfermagem no contato com o potencial doador de órgão destaca a reação focalizada no problema, que inclui a análise desse estressor, reconhecimento do sentimento que a situação desperta no profissional e a identificação de formas para sua resolução. ${ }^{13}$ Oncologistas clínicos costumam se envolver com atividades distintas ao seu cotidiano de trabalho, atividades de lazer e esportivas para enfrentar o dia a dia de trabalho, ${ }^{15}$ o que também se revelou na presente pesquisa.

O universo existencial abarca distintas dimensões que precisam ser integradas pelo sujeito na sua rotina diária, de forma que o profissional desenvolve papeis sociais variados (mãe/pai, filho (a), amigo (a), cidadão/cidadã, esportista, artista) que implicam responsabilizações e gratificações; se envolver com pessoas e atividades extra laborais pode diluir as angústias relacionadas a um contexto tenso de trabalho, à medida que exige dele um desligamento de uma ocupação para assumir outra. Os participantes ressaltaram a relevância das relações sociais desenvolvidas com amigos e colegas da equipe no cotidiano como estratégia de enfrentamento. ${ }^{14}$

Das falas analisadas identifica-se a necessidade de ajuda pscicológica para enfrentar os desafios do cuidado ao paciente oncológico e sua família. Ainda, aparecem a carência de programas de aperfeiçoamento permanente que auxiliem na expressão de sentimentos e no desenvolvimento de habilidades técnicas e psicossociais que oportunizem a ressignificação e adaptação saudável à realidade. Profissionais que cuidam de maneira empática vivenciam um abalo emocional, vários sentimentos emergem, principalmente, quando o desfecho é a morte, o que é percebida como um sinal de fracasso. 


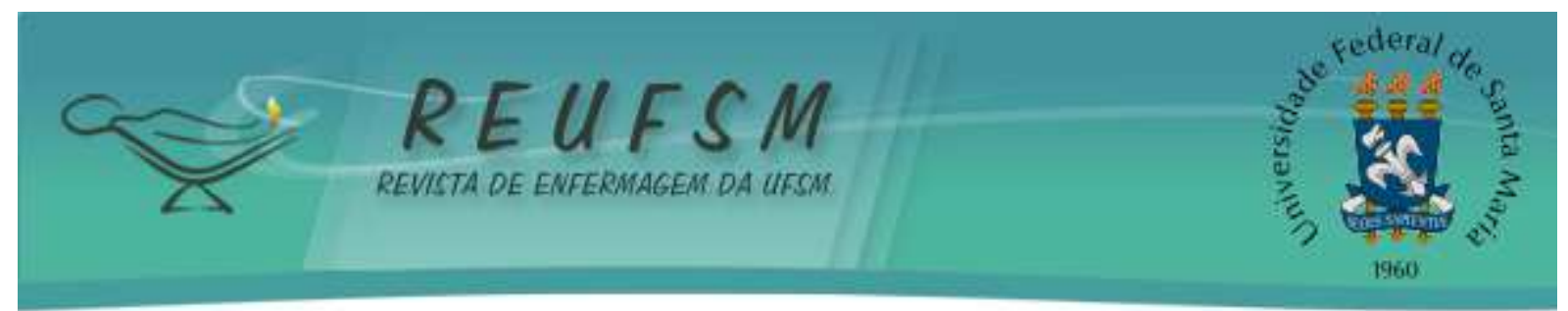

É possível identificar que as características institucionais influenciam nas reações de enfrentamento, uma vez que os participantes reivindicam a diminuição da carga horária de trabalho, como uma possibilidade de terem tempo para cultivar amizades e autocuidado. A equipe de enfermagem da unidade oncológica constatou que as atividades realizadas demandam elevada responsabilidade e qualificação, jornada de trabalho extensa e alta sobrecarga emocional, indo ao encontro da literatura. ${ }^{21}$ É relevante que o próprio profissional enfatize as suas necessidades e reconheça suas características como indivíduo, isto colabora para distinguir os seus próprios problemas aos do paciente, mas além disso, o ideal é que as instituições de saúde disponham de um suporte emocional e apoio psicológico. ${ }^{22-23}$

A análise dos depoimentos possibilita o reconhecimento de que as crenças, a fé e a oração são elementos construtivos e geradores de apoio e conforto no enfrentamento das dificuldades. $\mathrm{O}$ apego à espiritualidade e a busca de apoio em entidades superiores ajudam a equipe a lidar com as angústias vivenciadas. ${ }^{23}$ Cuidar da dimensão espiritual é experimentar a confiança em algo que vai muito além do aspecto biológico e, que muitas vezes, costuma trazer sensações menos aflitivas neste cotidiano.

Uma revisão, de dezoitos artigos internacionais sobre estratégias de enfrentamento utilizadas pela enfermagem em cuidado paliativo oncológico, apontou como estratégias baseadas no problema a gestão participativa; educação continuada e/ou permanente; reuniões de equipe para expressão de dificuldades em grupo e treinamentos, que favorecem a transformação do ambiente em oncologia; e mudanças na atitude dos profissionais para encarar o dia a dia de sofrimento e desgaste psíquico. Ainda, ressaltou um equilíbrio entre espiritualidade, sentimento e vida em família nas respostas centradas na emoção. ${ }^{8}$

As respostas de natureza emocional para enfrentar o desafiador contexto de trabalho em oncologia retratam, no presente estudo, tentativas de evitar o desconforto e proteger o ego de conflitos, garantindo a sobrevivência psíquica desses humanos que se ocupam de cuidar de outros humanos, em um processo intersubjetivo que mobiliza, inevitavelmente, afetos. Ao mesmo tempo, falam deste cenário de um lugar paradoxal ao assumido pelo paciente: do lugar de quem está saudável o suficiente para se emprestar ao outro na ação de cuidar, flexibilizando rotinas, amenizando a estrutura rígida do ambiente hospitalar, do lugar de quem pode valorizar a própria existência e saúde, bem como pode agradecer a uma entidade superior por não ter câncer, ressignificando seu próprio papel social, como pessoa solidária, para além de 


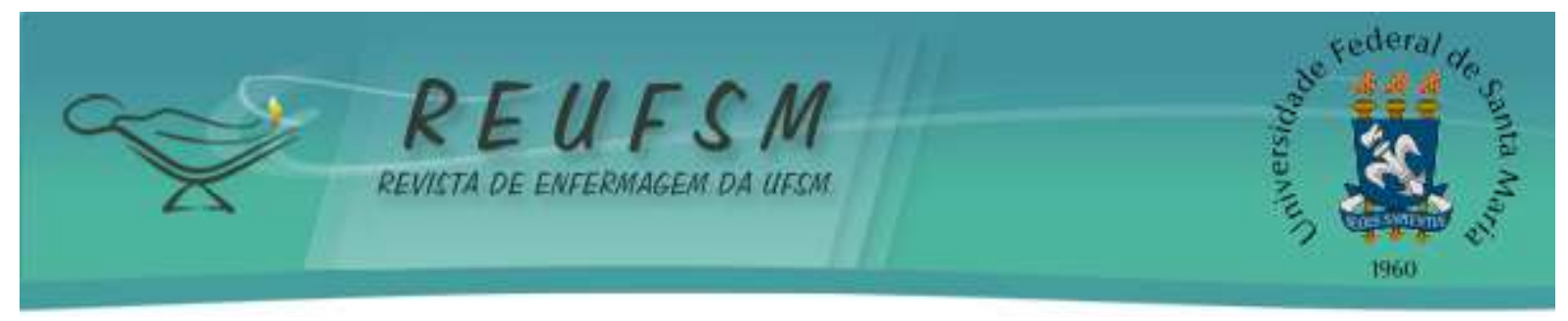

profissional de saúde. As falas dos participantes parecem expressar uma tentativa de autoconvencimento sobre a relevância social desse papel profissional/humanitário, que aliviaria o fardo de conviver com perdas e impotâncias. Ressignificar, como foi trazido, enquanto estratégia de coping, pode ser um mecanismo interessante para viver o cotidiano de cuidar em oncologia com satisfação pessoal e saúde mental.

Ao utilizar-se de estratégias centradas no problema, evidenciadas nesta pesquisa, o profissional de enfermagem se aproxima e confronta o problema, tendo a oportunidade de promover rearranjos pessoais para resolvê-lo ou se adaptar a ele com um nível máximo possível de sanidade e prazer. ${ }^{24}$ São estratégias que sinalizam um nível de consciência sobre a situação ameaçadora, no caso, o contato com pessoas gravemente enfermas, com a dor física e emocional, com o desmantelamento da vida e, sobretudo, um nível de consciência sobre a própria capacidade de enfrentá-la, superá-la ou suportá-la. É desenvolvendo o autocontrole, buscando suporte social e planejando formas de resolver situações práticas demandadas pelo paciente oncológico que a enfermagem age e reage para proteger sua própria sanidade psíquica no desenvolvimento do cuidar em oncologia. É importante acrescentar que o uso de uma estratégia de coping não restringe o uso de outras, podendo haver uma complementariedade entre elas. ${ }^{6}$

\section{CONSIDERAÇÕES FINAIS}

Prestar assistência ao paciente oncológico e familiares é uma vivência desafiadora para profissionais de enfermagem, representando um contexto de sofrimento em virtude das demandas afetivas e psicológicas que se impõem no cotidiano. Os profissionais são instigados a desenvolver permanentemente estratégias de enfrentamento para reduzir ou amenizar o impacto do contato com pacientes e familiares em sua saúde.

Ainda que consideradas menos resolutivas, as estratégias de coping predominantes no estudo são as centradas na emoção, que podem prejudicar a qualidade do cuidado à medida em que objetivam isolar o sujeito da realidade da qual tenta se defender, no caso o contato delicado com o paciente em condição de grave, sofrimento/prognóstico desfavorável e sua família. Assim, os profissionais revelam um processo de ressignificação que, por outro lado, favorece uma perspectiva pessoal positiva sobre seu ofício, bem como a aproximação empática junto a díade paciente-familiar. As estratégias centradas no problema destacam a 


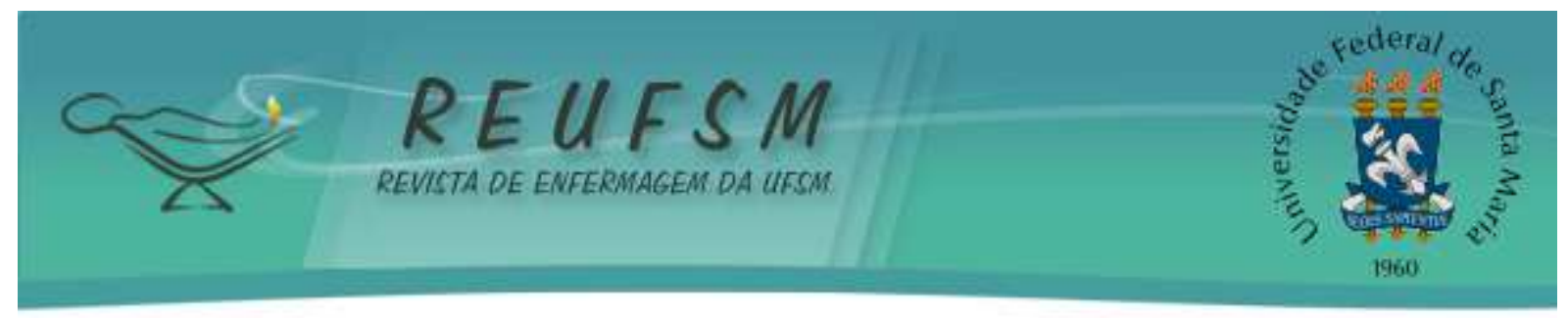

percepção dos profissionais sobre apoio, sobretudo institucional, para enfrentar coletivamente este contexto e desenvolver habilidades que tornem mais saudável e suportável esse contato.

A produção científica a respeito do sofrimento da enfermagem no cuidado com o paciente oncológico recomenda novas investigações sobre estratégias de enfrentamento que possam contribuir com o processo de trabalho em oncologia, ainda assim, são escassos as pesquisas na área. Considerando que novas estratégias podem ser aprendidas, inclusive em programas de treinamento de habilidades sociais, em grupos de expressão e de ajuda mútua e em outros processos psicoterápicos, é indispensável aprofundar a discussão sobre o tema entre os profissionais de saúde.

Ressalta-se a inegável variabilidade nas reações individuais, que inviabiliza a predição de respostas pessoais a eventos adversos, de forma que a presente investigação se propõe a descrever formas de enfrentamento situadas em um contexto e momento histórico, sendo incapaz de generalizar seus resultados, ainda que seu núcleo contribua com a compreensão do processo de trabalho de enfermagem em oncologia, sobretudo em sua dimensão ocupacional/de saúde do trabalhador de enfermagem. Também constitui limitação, em estudos desta natureza, a variabilidade de interpretações possíveis sobre cada estratégia de coping que emerge dos relatos.

Recomenda-se, a partir dos resultados do presente, espaços institucionais de escuta qualificada ao profissional, que oportunizem partilhamento de experiências, suporte emocional especializado destas equipes e programas ocupacionais institucionais de qualidade de vida para os profissionais imersos nesta realidade.

\section{REFERÊNCIAS}

1. Brasil. Ministério da Saúde. Instituto Nacional do Câncer. Estimativa 2016: incidência de câncer no Brasil/Instituto Nacional de Câncer. Rio de Janeiro: INCA; 2016.

2. Silva RP, Barbosa SC, Silva SS, Patricio DF. Burnout e estratégias de enfrentamento em profissionais de enfermagem. Arq Bras Psicol. 2015;67(1):130-45.

3. Salimena AMO, Teixeira SR, Amorin TV, Paiva ACPC, Melo MCSC. Estratégias de enfrentamento usadas por enfermeiros ao cuidar de pacientes oncológicos. REUFSM [Internet]. 2013 [acesso em 2018 maio 05];3(1):8-16. Disponível em: https://periodicos.ufsm.br/reufsm/article/view/6638/pdf.

4. Silva LC. O sofrimento psicológico dos profissionais de saúde na atenção ao paciente de câncer. Psicol Am Lat [Internet]. 2009 [acesso em 2018 abril 19];16. Disponível em: http://pepsic.bvsalud.org/scielo.php?script=sci_arttext\&pid=S1870-350X2009000100007. 


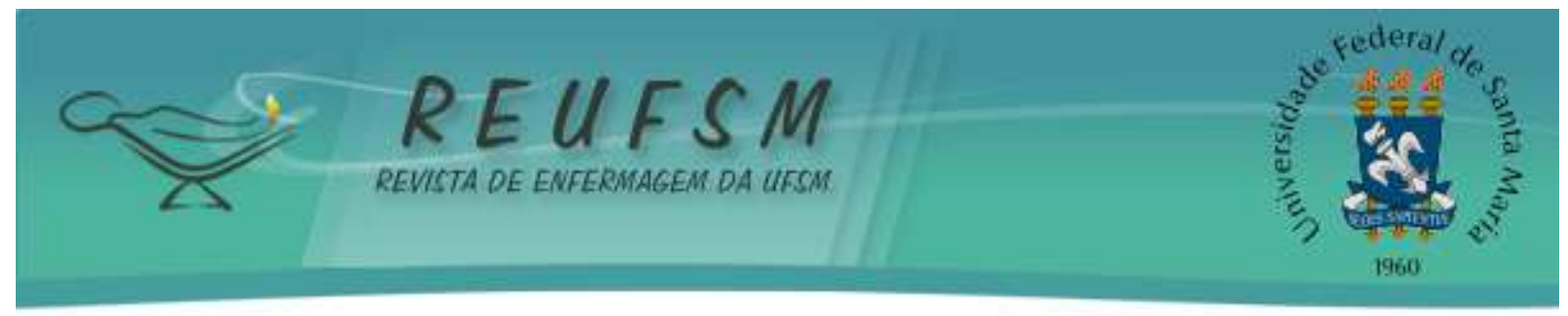

5. Morais ICPS, Martins ASP, Soares EO, Farias EA, Sampaio DD, Carvalho ML. Vivência do enfermeiro frente ao paciente oncológico em fase terminal: uma revisão da literatura. Rev Interd [Internet]. 2013 [acesso em 2016 mar 23];6(1):96-104. Disponível em: https://revistainterdisciplinar.uninovafapi.edu.br/index.php/revinter/article/viewFile/13/pdf_12.

6. Lazarus RS, Folkman S. Stress, appraisal and coping. New York: Springer; 1984.

7. Payne N. Occupational stressors and coping as determinants of burnout in female hospice nurses. Aust J Adv Nurs [Internet]. 2001 [acesso em 2018 abr 19];33(3). Disponível em: https://onlinelibrary.wiley.com/doi/pdf/10.1046/j.1365-2648.2001.01677.x.

8. Santos NAR, Gomes SV, Rodrigues MA, Santos J, Passos JP. Estratégias de enfrentamento utilizadas pelos enfermeiros em cuidados paliativos oncológicos: revisão integrativa. Cogitare Enferm [Internet]. 2016 [acesso em 2018 abr 19];21(3):1-8. Disponível em: http://www.saude.ufpr.br/portal/revistacogitare/wp-content/uploads/sites/28/2016/12/45063189600-1-PB.pdf.

9. Ayala ALM, Felicio ACR, Pachão J. Sofrimento dos profissionais que atuam no setor de oncologia em um hospital público de Joinville, SC. Rev Aten Saúde [Internet]. 2017 [acesso em 2018 abr 19];15,(51):106-17. Disponível em: http://seer.uscs.edu.br/index.php/revista_ciencias_saude/article/view/4376.

10. Faria DAP, Maia EMC. Ansiedades e sentimentos de profissionais de enfermagem nas situações de terminalidade em oncologia. Rev Latinoam Enferm [Internet]. 2007 [acesso em 2018 abr 19];15(6):1131-7. Disponível em: http://www.scielo.br/pdf/rlae/v15n6/pt_11.pdf.

11. Gomes SFS, Santos MMCC, Carolino ETMA. Psycho-social risks at work: stress and coping strategies in oncology nurses. Rev Latinoam Enferm [Internet]. 2013 [acesso em 2016 mar 16];21(6):1282-9. Disponível em: http://www.scielo.br/pdf/rlae/v21n6/pt_0104-1169rlae-0213-2365.pdf.

12. Minayo MCS. Desafio do conhecimento: pesquisa qualitativa em saúde. $14^{\circ}$ ed. São Paulo: Hucitec; 2014.

13. Lages MGG, Costa MAO, Lopes TR, Amorim FCS, Neto APA, Nascimento IRD, Costa MAO. Estratégias de enfrentamento de enfermeiros frente ao paciente oncológico pediátrico. Rev Bras Cancerol [Internet]. 2011 [acesso em 2016 nov 10];57(4):503-10. Disponível em: http://www.inca.gov.br/rbc/n_57/v04/pdf/06_artigo_estrategias_enfrentamento_enfermeiros_fre nte_paciente_oncologico_pediatrico.pdf.

14. Cano DS. Estratégias de enfrentamento psicológico de médicos oncologistas clínicos. Psicol Teor Pesqui [Internet]. 2016 [acesso em 2017 out 10];32(3):1-10. Disponível em: http://www.scielo.br/pdf/ptp/v32n3/1806-3446-ptp-e323211.pdf.

15. Bernandes C, Bitencourt JVOV, Parker AG, Luz KR, Vargas MAOV. Percepção de enfermeira(o)s frente ao paciente oncológico em fase terminal. Rev Baiana Enferm [Internet]. 2014 [acesso em 2016 nov 10];28(1):31-41. Disponível em: https://www.rebap.ufba.br/index.php/enfermagem/article/view/8883/8715.

16. Souza SS, Borenstein MS, Silva DMGV, Souza SS, Carvalho JB. Estratégias de enfrentamento da enfermagem no cuidado ao potencial doador de órgãos. RENE [Internet]. 


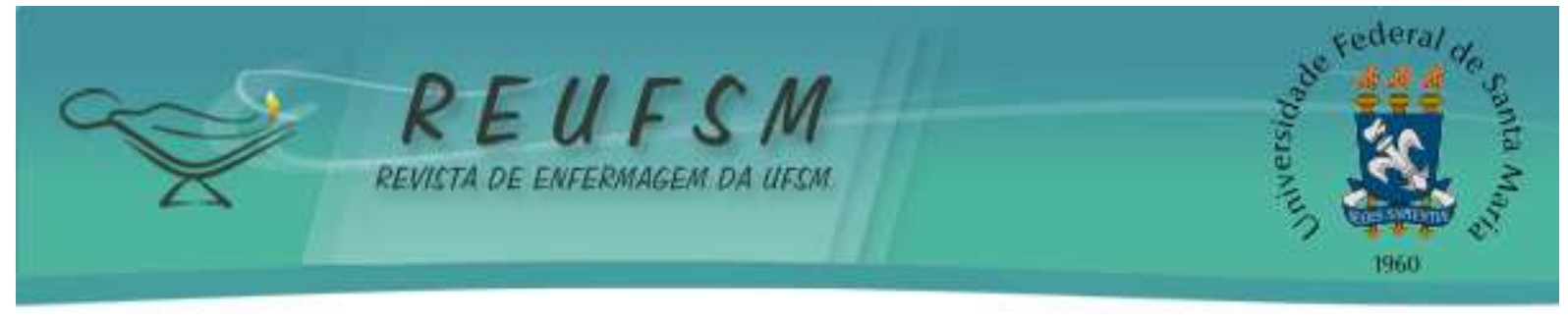

2013 [acesso em 2016 out 20];14(1):92-100. Disponível em: http://www.revistarene.ufc.br/revista/index.php/revista/article/view/96/pdf.

17. Umann J, Silva RS, Benavente SBT, Guido LA. O impacto das estratégias de enfrentamento na intensidade de estresse de enfermeiras de hemato-oncologia. Rev Gaúch Enferm [Internet]. 2014 [acesso em 2016 out 10];35(3):103-10. Disponível em: http://seer.ufrgs.br/index.php/RevistaGauchadeEnfermagem/article/view/44642/31520.

18. Martins JT, Bobroff MCC, Ribeiro RP, Costa VML, Cardelli AAM, Garanhani ML. Estratégias de enfrentamento às cargas de trabalho de enfermeiros de unidade de emergência. SMAD Rev Eetrôn Saúde Mental Alcool Drog [Internet]. 2012 [acesso em 2017 out 13];8(3):65-73. Disponível em: http://pepsic.bvsalud.org/pdf/smad/v8n3/pt_07.pdf.

19. Waldow VR, Fensterseifer LM. Saberes da enfermagem - a solidariedade como uma categoria essencial do cuidado. Esc Anna Nery Rev Enferm [Internet]. 2011 [acesso em 2017 nov 10];15(3):629-32. Disponível em: http://www.scielo.br/pdf/ean/v15n3/a27v15n3.pdf.

20. Guido LA, Silva RM, Goulart CT, Kleinubing RE, Umann J. Estresse e coping entre enfermeiros de unidade cirúrgica de hospital universitário. Rev RENE [Internet]. 2012 [acesso em 2016 out 20];13(2):428-36. Disponível em: http://www.periodicos.ufc.br/rene/article/view/3949.

21. Maronesi LC, Silva NR, Cantu SO, Santos AR. Indicadores de estresse e sobrecarga em cuidadores formais e informais de pacientes oncológicos. Estud Pesqui Psicol [Internet]. 2014 [acesso em 2016 set 18];14(3):877-92. Disponível em: pepsic.bvsalud.org/pdf/epp/v14n3/v14n3a10.pdf.

22. Pinto MH, Cruz MF, Cesarino CB, Pereira APS, Ribeiro RCHM, Beccaria LM. O cuidado de enfermagem ao paciente oncológico fora de possibilidade de cura: percepção de um grupo de profissionais. Cogitare Enferm [Internet]. 2011 [acesso em 2016 out 16];16(4):647-53. Disponível em: http://revistas.ufpr.br/cogitare/article/view/25433/17052.

23. Menegócio AM, Rodrigues L, Teixeira GL. Enfermagem oncologia: relação de afetividade ou meramente técnica? Ensaios Cienc Biol Agrar Saúde [Internet]. 2015 [acesso em 2016 set 18];19(3):118-23. Disponível em: http://www.pgsskroton.com.br/seer/index.php/ensaioeciencia/article/view/3191/2929.

24. Lima PC, Sabino KCV, Gouveia MTO, Avelino FVSD, Fernandes MA. Fatores estressores e as estratégias de enfrentamento utilizadas por enfermeiros hospitalares: revisão. Investig Enferm Imagen Desarr [Internet]. 2015 [acesso em 2017 out 10];17(2):51-65. Disponível

em:

http://revistas.javeriana.edu.co/index.php/imagenydesarrollo/article/view/8353/0.

Data de submissão: 04/10/2017

Data de aceite: $12 / 06 / 2018$

Autor correspondente: Pamela Karin Lazzaroto

E-mail: pame_lazzaroto@hotmail.com

Endereço: Rua Cabo João Loureiro, número 870, bairro Salete. Dionísio Cerqueira - SC

CEP: 89950-000 